Pacific Journal of Mathematic 


\title{
EXPECTED VALUES OF FUNCTIONALS WITH RESPECT TO THE ITO DISTRIBUTION
}

\author{
Michael Schilder
}

\begin{abstract}
Stochastic differential equations of the type (written symbolically)

(1.1) $\quad x^{(n)}(t)+m\left(t, x^{(n-1)}(t), x^{(n-2)}(t), \cdots, x^{\prime}(t), x(t), t\right)=z^{\prime}(t)$

$x(S)=a_{0}, x^{\prime}(S)=a_{1}, \cdots, x^{(n-1)}(S)=a_{n-1} \quad S \leqq t \leqq T$
\end{abstract}

where $z(t)$ is Brownian motion, arise in physics and engineering and are also the object of study of pure mathematicians. In this paper it will be shown that the integral associated with the distribution of the function $x(\cdot)$ may be expressed in terms of a Wiener integral with a weighting functional (the Radon-Nikodym derivative). Thus the expected values of functionals with respect to the distribution of $x(\cdot)$ can be easily and concisely expressed. Also it will be shown that certain partial differential equations of physics naturally have their solutions associated with this integral.

To proceed more precisely, following Ito [7], we rewrite the first order case of (1.1) as

$$
x(t)+\int_{S}^{t} m(u, x(u)) d u=z(t)
$$

and ask about solutions of (1.1)'. With certain conditions on $m(t, x)$ it is possible to conclude that for almost every $z(\cdot)$ (Wiener or Brownian motion measure) in $C[S, T]$, where $C[S, T]$ is the class of continuous functions on the interval $[S, T]$ whose value at $S$ is $a$, that $(1.1)^{\prime}$ has a unique solution $x(\cdot)$. See [2] for example. We express this by writing

$$
x=G z \text {. }
$$

Clearly now, the most natural definition for the distribution of $x(\cdot)$ is as follows:

$$
P(x(\cdot) \in A)=P_{W}\left(z \in G^{-1} A\right) .
$$

$P_{W}$ is Wiener measure, and $A$ is a set of functions contained in $C[S, T]$ which is such that $G^{-1} A$ is Wiener measurable. The distribution $P($ ) so defined will be called the Ito distribution and will be denoted from now on by $P_{I}\left(\right.$ ); the associated integral will be denoted by $E_{I}($ ).

This approach has been taken before. (See [4] and [5].) However in this paper it will be shown that explicit expressions for the expected values of various functionals arising in physics and engi- 
neering can be given in terms of Wiener integrals. In particular a number of the thermodynamic functions can be so expressed. Further, the results of this paper shed some light on the Feynman-Kac [8] formula for Wiener integrals.

2. The integral. In this section, the definiton of the Ito distribution which was given in the introduction, will be given rigorously and the integral with respect to it will be defined.

Let $T_{k}$ be the integral operator

$$
T_{k}(x)(t)=\int_{S}^{t} x(u) d u+a_{n-k}
$$

and let $y(t)=x^{(n-1)}(t)$.

We note that (1.1) may be written

$$
\begin{aligned}
y(t) & +\int_{S}^{t} m\left(u, y(u), T_{2}(y)(u), \cdots, T_{n}\left(T_{n-1}, \cdots,\left(T_{2} y\right)\right)(u)\right) d u \\
& =z(t) .
\end{aligned}
$$

As in the introduction, if certain conditions are put on $m\left(t, x_{n-1}\right.$, $\left.\cdots, x_{0}\right)$, then it follows that for almost every $z \in C[S, T]\left(z(S)=a_{n-1}\right)$ Wiener measure there is a unique solution to (2.1). We express this again by writing $y=G z$.

$\mathrm{As}$ in the introduction, this transformation induces a $\sigma$-field and a measure on the $y$ space, which we again call the Ito measure.

From now on the notation for the sets over which integration is performed will be left out if the meaning is clear.

We now have the following theorem:

THEOREM 1. If $F\left(x^{(n-1)}, \cdots, x\right)$ is a functional which is measurable and integrable with respect to the Ito distribution just defined and if for almost every $z \in C[S, T]$ (2.1) has a well defined solution, then

$$
\begin{aligned}
& \int F\left(x^{(n-1)}, \cdots, x\right) d P_{I}\left(x^{(n-1)}, \cdots, x\right) \\
& \quad=\int F\left(G z, T_{2} G z, \cdots, T_{n}\left(T_{n-1}, \cdots, T_{2}(G z)\right)\right) d P_{W}(z) .
\end{aligned}
$$

Proof. The proof follows immediately from the definitions.

There is the rather interesting and useful corollary.

CoRollary. Suppose $a_{n-j}(t)$ are continuous real valued functions for $S \leqq t \leqq T, j=1, \cdots, n$, and that $A$ is the matrix 


$$
A(t)=\left|\begin{array}{ccccc}
0 & 1 & 0 & \cdots & 0 \\
0 & 0 & 1 & \cdots & 0 \\
\vdots & \vdots & \vdots & & \vdots \\
-a_{0}(t) & -a_{1}(t) & -a_{2}(t) & \cdots & a_{n-1}(t)
\end{array}\right| .
$$

Let $\Phi(t)$ be the (matrix) fundamental solution to the equation

$$
\dot{\Phi}_{i k}(t)=\sum_{j}^{n} A_{i j}(t) \Phi_{j k}(t)
$$

Then

( i ) $\quad x(t)=\sum_{k l} \Phi_{1 k}(t) \int_{S}^{t} \Phi_{k l}^{-1}(u) A_{l_{n}}(u) z(u) d u$

is a solution to the integro-differential equation

$$
x^{(n-1)}(t)+\int_{S}^{t} \sum a_{n-j}(u) x^{j}(u) d u=z(t)
$$

(ii) $\quad x^{(j)}(t)=\sum_{k l} \Phi_{j k}(t) \int_{S}^{t} \Phi_{k l}^{-1}(u) A_{l n}(u) z(u) d u+\delta_{j n-1} z(t)$

(iii) The Ito distribution defined by

$$
\widetilde{x}^{(n)}(t)+\sum_{j} a_{n-j}(t) \widetilde{x}^{j}(t)=\dot{z}(t)
$$

and

$$
\widetilde{x}(s)=\widetilde{x}^{(1)}(s)=\widetilde{x}^{(2)}(s)=\cdots \widetilde{x}^{(n-1)}(s)=z(s)=0
$$

is Gaussian with

$$
E_{I}\left\{\widetilde{x}^{(j)}(t)\right\}=0 \quad j=0,1, \cdots, n-1 \quad \text { and } \quad S \leqq t \leqq T
$$

and

$$
\begin{aligned}
& E_{I}\left\{\widetilde{x}^{\left(j_{1}\right)}\left(t_{1}\right) \widetilde{x}^{\left(j_{2}\right)}\left(t_{2}\right)\right\}=\sum_{k_{1} l_{1} k_{2} l_{2}} \int_{S}^{t_{1}} \int_{S}^{t_{2}} \Phi_{j_{1} k_{1}}\left(t_{1}\right) \Phi_{k_{1} l_{1}}^{-1}\left(u_{1}\right) A_{l_{1} n}\left(u_{1}\right) \Phi_{j_{2} k_{2}}\left(t_{2}\right) \Phi_{k_{2} l_{2}}^{-1}\left(u_{2}\right) \\
& A_{l_{2} n}\left(u_{2}\right) \min \left(u_{1}-S, u_{2}-S\right) d u_{1} d u_{2} \\
& \quad+\sum_{k_{1} l_{1}} \Phi_{j_{1} k_{1}}\left(t_{1}\right) \int_{S}^{t_{1}} \Phi_{k_{1} l_{1}}^{-1}\left(u_{1}\right) A_{l_{1} n}\left(u_{1}\right) \min \left(u_{1}-S, t_{2}-S\right) d u_{1} \delta_{j_{1} n-1} \\
& \quad+\sum_{k_{2} l_{2}} \Phi_{j_{2} k_{2}}\left(t_{2}\right) \int_{S}^{t_{2}} \Phi_{k_{1} l_{2}}^{-1}\left(u_{2}\right) A_{l_{2} n}\left(u_{2}\right) A_{l_{2} n}\left(u_{2}\right) \min \left(u_{2}-S, t_{1}-S\right) d u_{2} \delta_{j n-1} \\
& \quad+\delta_{j_{1} n-1} \delta_{j_{2} n-1} \min \left(t_{1}-S, t_{2}-S\right) .
\end{aligned}
$$

Proof. (i) and (ii) follow by direct verification, which can be accomplished without differentiating $z$ by using integration by parts. To find the distribution $\widetilde{x}^{(j)}(t)$, the method of characteristic functions is used. By definition, the distribution of $\widetilde{x}^{(j)}(t)$ is that of $x^{j}(t)$. Thus from theorem 1, this definition, and (i) and (ii), 


$$
\begin{aligned}
\int \exp & {\left[i v \widetilde{x}^{(j)}(t)\right] P_{I}(\widetilde{x})=\int \exp \left[i v x^{(j)}(t)\right] P_{I}(x) } \\
= & E_{w}\left(\exp \left[i v\left(\sum_{k l} \Phi_{j k}(t) \int_{S}^{t} \widetilde{\Phi}_{k l}^{-1}(u) A_{l_{n}}(u) z(u) d u+\delta_{j n-1} z(t)\right)\right]\right) .
\end{aligned}
$$

The last Wiener integral is known to be

$$
\begin{aligned}
\exp [ & -v^{2} / 2\left(\sum_{k_{1} l_{1} k l_{2}} \int_{S}^{t} \int_{S}^{t} \Phi_{j_{k_{1}}}(t) \Phi_{k_{1} l_{1}}^{-1}\left(u_{1}\right) A_{l_{1} n}\left(u_{1}\right)\right. \\
& \times \Phi_{j_{2}}(t) \Phi_{k_{2} l_{2}}^{-1}\left(u_{2}\right) A_{l_{2} n}\left(u_{2}\right) \min \left(u_{1}-S, U_{2}-S\right) d u_{1} d u_{2} \\
& \left.\left.+2 \sum_{k_{1} l_{1}} \Phi_{j k_{1}}(t) \int_{S}^{t} \Phi_{k_{1} l_{1}}^{-1}(u) A_{l_{1} n}(u) \min (u-S, t-S) d u \delta_{j n-1}+\delta_{j n-1} t\right)\right] .
\end{aligned}
$$

Thus $\widetilde{x}^{(j)}(t) j=0, \cdots, n-1$ is Gaussian with mean zero and variance

$$
\begin{aligned}
\sum_{k_{1} l_{1} k_{2} l_{2}} \int_{S}^{t} \int_{S}^{t} \Phi_{j k_{1}}(t) \Phi_{k_{1} l_{1}}^{-1}\left(u_{1}\right) A_{l_{1} n}\left(u_{1}\right) \Phi_{j k_{2}}(t) \\
\quad \times \Phi_{k_{2} l_{2}}^{-1}\left(u_{2}\right) A_{l_{2}} n\left(u_{2}\right) \min \left(u_{1}-S, u_{2}-S\right) d u_{1} d u_{2} \\
+2 \sum_{k_{1} l_{1}} \Phi_{j k_{1}}^{-1}(t) \int_{S}^{t} \Phi_{k_{1} l_{1}}^{-1}(u) A_{l_{1} n}(u) \min (u-S, t-S) d u \delta_{j n-1}+\delta_{j n-1} t
\end{aligned}
$$

To calculate $E_{I}\left(\widetilde{x}^{j_{1}}\left(t_{1}\right) \tilde{x}^{j_{2}}\left(t_{2}\right)\right)$, we note that

$$
\begin{aligned}
& E_{I}\left(\widetilde{x}^{j_{1}}\left(t_{1}\right) \widetilde{x}^{j_{2}}\left(t_{2}\right)\right)=E_{I}\left(x^{j_{1}}\left(t_{1}\right) x^{j_{2}}\left(t_{2}\right)\right) \\
& =E_{w^{\prime}}\left(\left(\sum_{k_{1} l_{1}} \Phi_{j_{1} k_{1}}\left(t_{1}\right) \int_{S}^{t_{1}} \Phi_{k_{1} l_{1}}^{-1}\left(u_{1}\right) A_{l_{1} n}\left(u_{1}\right) z\left(u_{1}\right) d u_{1}+\delta_{j_{1} n-1} z\left(t_{1}\right)\right)\right. \\
& \left.\left(\sum_{k_{2} l_{2}} \Phi_{j_{2} k_{2}}\left(t_{2}\right) \int_{S}^{t_{2}} \Phi_{k_{2} l_{2}}^{-1}\left(u_{2}\right) A_{l_{2} n}\left(u_{2}\right) z\left(u_{2}\right) d u_{2}+\delta_{j_{2}} z\left(t_{2}\right)\right)\right) \\
& =\sum_{k_{1} l_{1} k_{2} l_{2}} \int_{S} \int_{S}^{t_{1}} \int_{S}^{t_{2}} \Phi_{j_{1} k_{1}}\left(t_{1}\right) \Phi_{k_{1} l_{1}}^{-1}\left(u_{1}\right) A_{l_{1} n}\left(u_{1}\right) \Phi_{j_{2} k_{2}}\left(t_{2}\right) \\
& \quad \times \Phi_{k_{2} l_{2}}^{-1}\left(u_{2}\right) A_{l_{2} n}\left(u_{2}\right) \min \left(u_{1}-S, u_{2}-S\right) d u_{1} d u_{2} \\
& \quad+\sum_{k_{1} l_{1}} \Phi_{j_{1} k_{1}}\left(t_{1}\right) \int_{S}^{t_{1}} \Phi_{k_{1} l_{1}}^{-1}\left(u_{1}\right) A_{l_{1} n}\left(u_{1}\right) \min \left(u_{1}-S, t_{2}-S\right) d u, \delta_{j_{1} n-1} \\
& \quad+\sum_{k_{2} l_{2}} \Phi_{j_{2} k_{2}}\left(t_{2}\right) \int_{S}^{t_{2}} \Phi_{k_{2} l_{2}}^{-1}\left(u_{2}\right) A_{l_{2} n}\left(u_{2}\right) \min \left(u_{2}-S, t_{1}-S\right) d u_{1} \delta_{j_{2} n-1} \\
& \quad+\delta_{j_{1} n-1} \delta_{j_{2} n-1} \min \left(t_{1}-S, t_{2}-S\right),
\end{aligned}
$$

which completes the proof of the corollary. For another from of this corollary, see [10].

3. The transformation theorem. It, unfortunately, is not nearly as easy to invert (in the sense of (1.2)) the general nonlinear $n^{\text {th }}$ order ordinary differential equation as it is the linear one. It, therefore, is necessary to use more general methods to study the Ito distribution. It is an interesting fact that inverting (2.1) is in some 
way equivalent to changing variables in the Wiener integral. In this section, this idea will be made more precise. The analysis leans heavily on the work of Cameron and Martin who developed the transformation theory of the Wiener integral with their students.

TheOREm 2. Suppose $m\left(t, x_{n-1}, \cdots, x_{1}, x_{0}\right)$ is a real valued, continuous, and continuously differentiable function on $R^{n+1}$. Suppose also that for almost every $z \in C[S, T](2.1)$ has a unique solution. Then, if $F\left(x^{(n-1)}, x^{(n-2)}, \cdots, x^{\prime} x\right)$ is a measurable and integrable functional on the Ito space defined by (1.1) and the conventions agreed upon at the beginning of $\S 2$,

$$
\begin{aligned}
& \int F\left(x^{(n-1)}, x^{(n-2)}, \cdots, x^{\prime}, x\right) d P_{I}\left(x^{(n-1)}, x^{(n-2)}, \cdots, x^{\prime}, x\right) \\
&= \int F\left(y, T_{2} y, \cdots, T_{n}\left(T_{n-1}, \cdots,\left(T_{2} y\right)\right)\right) \\
& \times \exp \left[\int_{S}^{T} p\left(t, T_{2} y(t), \cdots, T_{n}\left(T_{n-1}, \cdots,\left(T_{2} y\right)\right)(t)\right) d t\right] \\
& \times \exp \left[-M\left(T, T_{2} y(T), \cdots, T_{n}\left(T_{n-1}, \cdots,\left(T_{2} y\right)\right)(T)\right)\right] d P_{w}(y) \\
& \quad \times \exp \left[M\left(S, a_{n-1}, \cdots, a_{0}\right)\right] .
\end{aligned}
$$

where

$$
M\left(t, x_{n-1}, \cdots, x_{0}\right)=\int_{0}^{x_{n-1}} m\left(t, u, x_{n-2}, \cdots, x_{0}\right) d u
$$

and

$$
p\left(t, x_{n-1}, \cdots, x_{0}\right)=\frac{1}{2} m_{x_{n-1}}+M_{t}+\sum_{j=2}^{n} M_{x_{n-j}} x_{n-j}-\frac{1}{2} m^{2} .
$$

It will be noted that Theorem 2 allows one to express the Ito integral without solving (2.1) for almost every $z \in C[S, T]$.

Proof. From Theorem (I) it follows that

$$
\begin{aligned}
& \int F\left(x^{n-1}, x^{n-2}, \cdots, x\right) d P\left(x^{n-1}, \cdots, x_{0}\right) \\
& \quad=\int F\left(y, T_{2} y, \cdots, T_{n}\left(T_{n-1}, \cdots,\left(T_{2} y\right)\right)\right) d P_{w}(z) .
\end{aligned}
$$

The result then follows immediately from [1] equation (3.6).

Note that Cameron uses a slightly different definition of the Wiener integral that usual. The result here is also generalized to include the case of arbitrary final time $T$ and arbitrary initial values $a_{n-1}, \cdots, a_{0}$, and time $S$. 
4. Partial differential equations. In this section, we will show that the solutions of certain partial differential equations of physics are naturally given by integrals of the form (3.1). Let

$$
\begin{aligned}
H\left(x_{n-1}, \cdots, x_{0} ; b_{n-1}, \cdots, b_{0}\right) & =1 & & \text { if } x_{n-1} \leqq b_{n-1}, \cdots, x_{0} \leqq b_{0} \\
& =0 & & \text { otherwise. And let }
\end{aligned}
$$

$$
\begin{aligned}
p\left(t, x_{n-1}, \cdots, x_{0}\right)= & \frac{1}{2} m_{x_{n-1}}\left(t, x_{n-1}, \cdots, x_{0}\right)+M_{t}\left(t, x_{n-1}, \cdots, x_{0}\right) \\
& +\sum M_{x_{n-j}}\left(t, x_{n-1}, \cdots, x_{0}\right) x_{n-j}-\frac{1}{2} m^{2}\left(t, x_{n-1}, \cdots, x_{0}\right) .
\end{aligned}
$$

We note that with the conventions agreed upon at the beginning of $\S 2$,

$$
\begin{aligned}
& P\left(b_{n-1}, \cdots, b_{0} ; a_{n-1}, \cdots, a_{0} ; t\right)=\text { probability }\left(x^{(n-1)}(t)\right. \\
& \left.\quad \leqq b_{n-1}, \cdots, x(t) \leqq b_{0} \mid x^{(n-1)}(S)=a_{n-1}, \cdots, x(S)=a_{0}\right)
\end{aligned}
$$

is a well defined function of $2 n+2$ variables. The following theorem follows immediately from Theorem 2 .

THEOREM 3. If $m\left(t, x_{n-1}, \cdots, x_{0}\right)$ satisfies the conditions of Theorem 2, then,

$$
\begin{aligned}
P\left(b_{n-1}, \cdots, b_{0} ; a_{n-1}, \cdots, a_{0} ; t\right) \\
=\int H\left(y(t), \cdots, T_{n}\left(T_{n-1}, \cdots,\left(T_{2} y\right)\right)(t) ; b_{n-1}, \cdots, b_{0}\right) \\
\quad \times \exp \left[\int_{S}^{T} p\left(u, y(u), \cdots, T_{n}\left(T_{n-1}, \cdots,\left(T_{2} y\right)\right)(u)\right) d u\right] \\
\quad \times \exp \left[-M\left(T, y(T), \cdots, T_{n}\left(T_{n-1}, \cdots,\left(T_{2}(y)(T)\right)\right] d P_{w}(y)\right.\right. \\
\quad \times \exp \left[M\left(S, a_{n-1}, \cdots, a_{0}\right)\right] .
\end{aligned}
$$

Theorem 3 shows that the function $P\left(b_{n-1}, \cdots, b_{0} ; a_{n-1}, \cdots, a_{0} ; t\right)$ may be expressed in terms of a Wiener integral. It will presently be shown for the first order equation, anyway, that the Ito distribution, defined in $\S 2$ is a Markov process, and thus it follows that $P\left(b_{n-1}, \cdots\right.$, $\left.b_{0} ; a_{n-1}, \cdots, a_{0} ; t\right)$ is its distribution function. It also follows that $P\left(b_{n-1}, \cdots, b_{0} ; a_{n-1}, \cdots, a_{0} ; t\right)$ solves the backward and forward diffusion equations (the Fokker-Planck equation). We state and prove this rigorously in Theorem 4, for first order equations.

THEOREM 4. Let $\delta(a-b)$ be the delta function and let $P(b ; a ; S+$; $S)$ mean the limit as $T$ approaches $S$ from above. Suppose $m(T, x)$ satisfies the conditions of Theorem 2, and $m(T, x) \leqq K\left(1+x^{2}\right)^{1 / 2}$ where $K$ is a positive constant. Suppose also that

$$
p(t, x)=\frac{1}{2} m_{x}+M_{t}-\frac{1}{2} m^{2}
$$


is uniformly Holder continuous and bounded from below. Then it follows that the differential equations

$$
\begin{gathered}
\frac{\partial}{\partial S}[P(b ; a ; T ; S)]+M(S, a) \frac{\partial}{\partial a}[P]+\frac{1}{2} \frac{\partial^{2}}{\partial a^{2}}[P]=0 \\
P(b ; a ; S+; S)=1 \text { if } a \leqq b \\
=0 \text { if } a>b
\end{gathered}
$$

have well defined solutions. If

(4.3) $\quad P(a ; b ; T ; S)$

$=\int H(y(T) ; b) \exp \left[\int_{S}^{T} p(t, y(t)) d t-M(T ; y(T))\right] d P_{w}(y) \exp [M(S, a)]$,

it follows that $P$ solves (4.1), and if

$$
\begin{aligned}
P^{\prime}(b ; a ; T ; S)= & \int \exp \left[\int_{S}^{T} p(t, y(t)) d t\right] d P_{w}(y \mid y(T)=b) \\
& \times \exp [M(T, b)-M(S, a)] \\
& \left.\times(2 \pi(T-S))^{-1 / 2} \exp [-1 / 2(T-S))(b-a)^{2}\right]
\end{aligned}
$$

then it follows that $P^{\prime}$ solves (4.2).

$P_{w}(y \mid y(t)=b)$ is Wiener measure (probability) conditioned on $y(S)=a, y(T)=b$.

Proof. It will first be shown that

$\frac{\partial}{\partial b}[P(b ; a ; T ; S)]=P^{\prime}(b ; a ; T ; S)$ where $P^{\prime}$ is defined by $(4.4)$.

$$
\begin{aligned}
P^{\prime}(b ; a ; T ; S)= & \lim _{h \rightarrow 0}[P(b+h, a ; T ; S)-P(b ; a ; T ; S)] \frac{1}{h} \\
= & \lim _{h \rightarrow 0} \frac{1}{h} \int \exp \left[\int_{S}^{T} p(t, y(t)) d t-M(T, y(T))\right] \\
& \times H(y(T) ; b+h)-H(y(T) ; b)) d P_{w}(y) \exp [M(S, a)] .
\end{aligned}
$$

Since $\left.\lim _{h \rightarrow 0} \frac{1}{h} \int H(y(T) ; b+h)-H(y(T) ; b)\right) d P_{w}(y)$

$$
\begin{aligned}
& =\lim _{h \rightarrow 0}(2 \pi(T-S))^{-1 / 2} \int_{b}^{b+h} \exp \left[-(1 / 2(T-S))(u-a)^{2}\right] d u \\
& =(2 \pi(T-S))^{-1 / 2} \exp \left[-(1 / 2(T-S))(b-a)^{2}\right],
\end{aligned}
$$


it follows that $\partial / \partial b[P]=P^{\prime}$ as was to be shown.

From Doob [3] Chap. VI, $\S 3$ and the assumption of this theorem, it follows that process $x(t)$, defined by (2.1) and our conventions, is a Markov process and that the following limits exist and have the indicated values.

$$
\begin{aligned}
& \lim _{h \rightarrow 0} \frac{1}{h} \int[x(S+h)-x(S)] d P_{I}(x)=m(S, a) \\
& \lim _{h \rightarrow 0} \frac{1}{h} \int[x(S+h)-x(S)]^{2} d P_{I}(x)=1
\end{aligned}
$$

and that

$$
P_{d}(|x(T)-x(S)|>\varepsilon)=o(T-S) .
$$

From [9] Theorem 1, it follows that $P^{\prime}$ has sufficient derivatives for (4.2) to make sense; from [6] and the above, it then follows that $P^{\prime}$ solves (4.2) except for (possibly) the initial conditions. Since $P^{\prime}$ has sufficient derivatives for (4.2) to make sense, it can be seen that $P$ has sufficient derivatives for (4.1) to make sense and thus from [6] and the above, again it follows that $P$ solves (4.1) except for (possibly) the initial conditions. The initial conditions for both (4.1) and (4.2) follow easily from (4.7). This shows Theorem 4.

The integral in (4.4) is, of course, very close to the Feynman integral of quantum mechanics; and, by way of Theorem 4, one is led to a rather interesting physical interpretation of the Schrodinger equation.

We now take a slightly different direction and note that $U(t, S, \alpha)=$ $E_{I}(y(t))=\int y(t) d P_{I}(y)$ has a physical interpretation as the expected position of a particle moving in one dimension at time $t$ which, at time $S$, was at $a . \partial /\left.\partial t[U(t, S, a)]\right|_{t=S}$ then has a physical interpretation as the excepted velocity of the particle at time $S$ given the position of time $S$ is $a$. It is interesting that this expression solves an equation similar to the one-dimensional Navier-Stokes equation. This fact will be shown in Theorem 5 .

THEOREm $5^{1}$. Suppose $m(T, x)$ satisfies the conditions of Theorem 4 and $m_{x x}(t, x)$ exists and is continuous and let

$$
\begin{aligned}
& U(T, t, S, a)=E_{I}(y(t)) \\
& \quad=\int y(t) \exp \left[\int_{S}^{T} p(u, y(u)) d u-M(T, y(T))\right] d P_{w}(y) \exp [M(S, a)]
\end{aligned}
$$

1 Professor M. Donsker has shown that a ratio of Wiener integrals similar to (4.9) satisfies (4.10). Professor Donsker, however, used a different method of proof. 
then

$$
\lim _{t \downarrow S} 1 /(t-S)[U(T, t, S, a)-U(T, S, S, a)]
$$

exists, and if

$$
V(T, S, a)=\lim _{t \downarrow S} 1 /(t-S)[U(T, t, S, a)-U(T, S, S, a)]
$$

$V$ satisfies the equation,

$$
-V_{S}+V V_{a}=-p_{x}(a, S)+\frac{1}{2} V_{a a}
$$

with terminal condition $V(T, T, a)=m(T, a) . \quad$ The term $\exp [M(S, a)]$ may be expressed as

$$
\exp [M(S, a)]=1 / \int \exp \left[\int_{S}^{T} p(t, y(t)) d t-M(T, y(T))\right] d P_{w}(y) .
$$

Proof. From (4.5), it follows immediately that the indicated limit exists and that $V(T, S, a)=m(S, a)$, and therefore $V(T, T, a)=m(T, a)$. But $M(T, a)$ is defined as

$$
M(T, a)=\int_{0}^{a} m(T, u) d u
$$

and $p(S, a)$ is defined as

$$
p(S, a)=\frac{1}{2} m_{a}(S, a)+M_{s}(S, a)-\frac{1}{2} m^{2}(S, a)
$$

and thus

$$
p_{a}(S, a)=\frac{1}{2} m_{a a}(S, a)+m_{S}(S, a)-m(S, a) m_{a}(S, a) .
$$

(4.10) thus follows immediately. (4.11) follows from the relationship

$$
\begin{aligned}
1=P(\infty, a, T, S)=\exp & {\left[\int_{S}^{T} p(t, y(t)) d t\right.} \\
& -M(T, y(T))] d P_{w}(y) \exp [M(S, a)] .
\end{aligned}
$$

Theorem 5 shows that the solution to (4.10) may be expressed in terms of Wiener integrals, if it is known that the solution to (4.10) exists and has certain properties. The fact that the solution for earlier times is given in terms of later times and that the sign of $V_{S}$ is minus may be fixed by reversing the direction of the Wiener paths. More details and applications of the theory presented here will be given in a later work. 


\section{REFERENCES}

1. R. H., Cameron, Nonliner volterra functional equations, Journal d'Analuse Mathématique 5 (1957), 136-182.

2. Differential equations involving a parametric function, Proc. Amer. Math. Soc. 8 (1957), 834-840.

3. J. L. Doob, Stochastic processes, New York, 1953.

4. E. B. Dynkin, Markov Processes, New York, 1965.

5. I. V. Girsanov, On the transformation of a class of stochastic processes by means of an absolutely continuous change of measure, Teor. Veroyatnost. i Primen 5 (1960), 314-330.

6. B. V. Gnedenko, The Theory of Probability, New York, 1962.

7. K. Ito, On stochastic differential equations, Mem. Am. Math. Soc. 4 (1951).

8. M. Kac, On some connections between probability theory and differential and integral equations, Proc. Second Berkeley Symposium on Math. Statistics and Probability, 189-215, University of California Press, Berkeley and Los Angeles, 1951.

9. M. Rosenblatt, On a class of Markov processes, Trans. Amer. Math., Soc. 71 (1951). 10. M. C. Wang and G. E. Uhlenbeck, On the Theory of the Brownian Motion II, Rev, of Mod. Phy. Vol. 17, Numbers 2 and 3 (1945).

Received February, 24, 1967.

\section{Aerospace Research Center}

General Precision Systems Inc.

LitTle Falls, N. J. 


\section{PACIFIC JOURNAL OF MATHEMATICS}

\section{EDITORS}

\section{H. ROYDEN}

Stanford University

Stanford, California
J. DugundJI

Department of Mathematics

Rice University

Houston, Texas 77001

RICHARD ARENS

University of California

Los Angeles, California 90024

Seattle, Washington 98105

\section{ASSOCIATE EDITORS}
E. F. BeCKENBACH
B. H. NeumanN
F. WOLF
K. YOSIDA

\section{SUPPORTING INSTITUTIONS}

\author{
UNIVERSITY OF BRITISH COLUMBIA \\ CALIFORNIA INSTITUTE OF TECHNOLOGY \\ UNIVERSITY OF CALIFORNIA \\ MONTANA STATE UNIVERSITY \\ UNIVERSITY OF NEVADA \\ NEW MEXICO STATE UNIVERSITY \\ OREGON STATE UNIVERSITY \\ UNIVERSITY OF OREGON \\ OSAKA UNIVERSITY \\ UNIVERSITY OF SOUTHERN CALIFORNIA
}

\author{
STANFORD UNIVERSITY \\ UNIVERSITY OF TOKYO \\ UNIVERSITY OF UTAH \\ WASHINGTON STATE UNIVERSITY \\ UNIVERSITY OF WASHINGTON \\ * * * * \\ AMERICAN MATHEMATICAL SOCIETY \\ CHEVRON RESEARCH CORPORATION \\ TRW SYSTEMS \\ NAVAL WEAPONS CENTER
}

Mathematical papers intended for publication in the Pacific Journal of Mathematics should be in typed form or offset-reproduced, double spaced with large margins. Underline Greek letters in red, German in green, and script in blue. The first paragraph or two must be capable of being used separately as a synopsis of the entire paper. It should not contain references to the bibliography. Manuscripts, in duplicate if possible, may be sent to any one of the four editors. All other communications to the editors should be addressed to the managing editor, Richard Arens, University of California, Los Angeles, California 90024.

Each author of each article receives 50 reprints free of charge; additional copies may be obtained at cost in multiples of 50 .

The Pacific Journal of Mathematics is published monthly. Effective with Volume 16 the price per volume (3 numbers) is $\$ 8.00$; single issues, $\$ 3.00$. Special price for current issues to individual faculty members of supporting institutions and to individual members of the American Mathematical Society: $\$ 4.00$ per volume; single issues $\$ 1.50$. Back numbers are available.

Subscriptions, orders for back numbers, and changes of address should be sent to Pacific Journal of Mathematics, 103 Highland Boulevard, Berkeley 8, California.

Printed at Kokusai Bunken Insatsusha (International Academic Printing Co., Ltd.), 7-17, Fujimi 2-chome, Chiyoda-ku, Tokyo, Japan.

PUBLISHED BY PACIFIC JOURNAL OF MATHEMATICS, A NON-PROFIT CORPORATION

The Supporting Institutions listed above contribute to the cost of publication of this Journal, but they are not owners of publishers and have no responsibility for its content or policies. 


\section{Pacific Journal of Mathematics \\ Vol. 25, No. $2 \quad$ October, 1968}

Martin Aigner, On the tetrahedral graph ..................... 219

Gregory Frank Bachelis, Homomorphisms of annihilator Banach

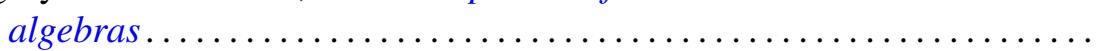

Phillip Alan Griffith, Transitive and fully transitive primary abelian groups.......................................... 249

Benjamin Rigler Halpern, Fixed points for iterates . . . . . . . . . . . . . 255

James Edgar Keesling, Mappings and dimension in general metric spaces ......................................... 277

$\mathrm{Al}$ (Allen Frederick) Kelley, Jr., Invariance for linear systems of ordinary differential equations ................................ 289

Hayri Korezlioglu, Reproducing kernels in separable Hilbert spaces . . . . . 305

Gerson Louis Levin and Wolmer Vasconcelos, Homological dimensions and Macaulay rings ................................. 315

Leo Sario and Mitsuru Nakai, Point norms in the construction of harmonic

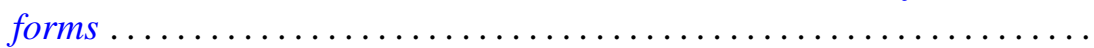

Barbara Osofsky, Noncommutative rings whose cyclic modules have cyclic injective hulls ..................................... 331

Newton Tenney Peck, Extreme points and dimension theory........... 341

Jack Segal, Quasi dimension type. II. Types in 1-dimensional spaces ...... 353

Michael Schilder, Expected values of functionals with respect to the Ito distribution ...

Grigorios Tsagas, A Riemannian space with strictly positive sectional curvature

John Alexander Williamson, Random walks and Riesz kernels . . 